\title{
MUDANÇA AMBIENTAL E \\ REORIENTAÇAOO ESTRATÉGICA: ESTUDO DE CASO EM INSTITUIÇÃO BANCÁRIA
}

Clóvis L. Machado-da-Silva Professor de Estratégia, Mudança e Análise Organizacional do Centro de Pesquisa e Pós-Graduação em Administração da Universidade Federal do Paraná. E-mail:clms@ceppad.ufpr.br

Bruno H. Rocha Fernandes Professor do Centro de Pesquisa e Pós-Graduação em Administração da Universidade Federal do Paraná e do ISAD/PUC.

RESUMO: Pesquisas recentes vêm demonstrando que organizações bem-sucedidas tendem a encontrar dificuldades em reorientar prontamente suas estratégias de ação diante de novas circunstâncias ambientais. Geralmente, mudanças que impliquem reorientação estratégica da organização tendem a ser adiadas até a ocorrência de situação de crise, quando já se passou o melhor momento de implementá-las. No presente estudo, focaliza-se essa problemática mediante análise do impacto do Plano Real em uma organização do setor financeiro, o Banco Bamerindus do Brasil S.A. A análise longitudinal, de natureza descritivo-qualitativa, abrange o período compreendido entre janeiro de 1992 e dezembro de 1996.

ABSTRACT: Recent research has demonstrated that successful organizations tend to have difficulties in promptly reorienting their strategies in facing new environmental circumstances. In a general view, changes that imply organizational strategic reorientation are postponed until crisis occurrence, when the best moment for fundamental changes has already gone. The present study focuses this problematical challenge by means of analysis of Brazilian Plano Real impact on Bamerindus banking organization. This longitudinal analysis simultaneously descriptive and qualitative comprehends January 1992-December 1996 period.

PALAVRAS-CHAVE: mudança organizacional, estratégia organizacional, ambiente organizacional, reorientação estratégica.

KEY WORDS: organizational change, organizational strategy, organization environment, strategic reorientation. 
As recentes transformações na ordem econômica mundial vêm afetando, em maior ou menor grau, as estratégias das organizações empresariais e mesmo daquelas que não se enquadram nessa categoria. $\mathrm{O}$ avanço da tecnologia da informação, a desregulamentação da atividade financeira, os acordos de remoção mútua de barreiras comerciais entre países, entre outros, configuram mudanças significativas no ambiente empresarial deste final de século. Em especial, é possível observar incremento da concorrência entre empresas, elevação do padrão de exigência dos consumidores e aumento contundente da velocidade em que determinadas tecnologias se tornam obsoletas.

As mudanças que já vêm ocorrendo e aquelas passíveis de se anteverem no cenário brasileiro e internacional representam forte estímulo às organizações para repensarem suas estratégias, visando à adaptação à nova realidade de competição ambiental. No entanto, por maiores que se revelem as transformações no ambiente, pesquisas recentes demonstram a limitada capacidade das organizações de empreenderem mudanças significativas em situação de funcionamento bem-sucedido. Geralmente, mudanças profundas, que implicam reorientação estratégica da organização, tendem a ser adiadas, só se verificando em momentos de crise, quando, na maioria das vezes, já se passou o melhor momento de implementálas. Ao que parece, organizações só conseguem conviver razoavelmente bem com mudanças incrementais que não impliquem reorientação do arquétipo organizacional. ${ }^{1}$

$\mathrm{Se}$ os resultados das pesquisas recentes são passíveis de generalização, devem intrigar qualquer estudioso do assunto as razões que levam as organizações a adiar a reorientação estratégica até o ponto em que sua eficácia possa ser questionada ou, no limite, não ser mais possível implementá-la. Um conjunto de fatores interligados e complementares parece oferecer resposta plausível à problemática de que organizações bem-sucedidas tendem a encontrar dificuldades em reorientar prontamente suas estratégias diante de novas circunstâncias ambientais: a) a existência de reservas financeiras e de reservas psicológicas, b) a estabilidade dos esquemas interpretativos e das estruturas organizacionais, c) as deficiências de aprendizagem e a existência de mecanismos de atribuição e d) o contexto institucional de referência.

A fim de verificar se esses fatores permitem responder ao problema em exame numa situação concreta, selecionaram-se, de um lado, uma mudança ambiental relevante, a saber, a implantação do Plano Real e, de outro, o Banco Bamerindus do Brasil S.A., organização bem-sucedida, que entrou gradualmente em crise após o advento da mudança em referência, ocorrida especificamente em fevereiro de 1994, mas com desdobramentos importantes sobretudo nos meses subseqüentes. A escolha de instituição do setor bancário deu-se, obviamente, pelo potencial de repercussão imediata do Plano Real em organizações da área financeira. O período em estudo está compreendido entre janeiro de 1992 e dezembro de 1996, o que representa dois anos e meio antes e dois anos e meio depois da implantação do referido plano econômico. Por sua vez, a seleção do Bamerindus justifica-se pelo seu aparente sucesso antes da implantação do Plano Real e, após, sucessivamente, pelo desajuste ambiental crescente, pelo atraso no sentido de levar a cabo mudanças estratégicas e pelo agravamento da situação de crise, que culminou com sua venda a grupo bancário internacional, em março de 1997.

\section{BASE TEÓRICO-EMPÍRICA}

As estratégias organizacionais são usualmente delineadas a partir de um conjunto de forças que se sustentam, de um lado, os valores e crenças compartilhados pelo grupo de dirigentes e, de outro, a forma de distribuição do poder organizacional entre os membros da coalizão dominante. Valores e crenças compartilhados possibilitam modos de interpretação intersubjetiva que sustentam a estratégia; já a distribuição do poder determina a predominância de algumas formas de interpretação sobre outras e, conseqüentemente, a escolha de alguns cursos de ação em detrimento de outros. As articulações entre valores e crenças e entre estes e o sistema de poder em uma organização compõem o chamado paradigma estratégico, ${ }^{2}$ ou os modelos mentais, ${ }^{3}$ ou, ainda, os esquemas interpretativos ${ }^{4}$.

Todavia o delineamento de estratégias não obedece apenas à lógica interna relacionada aos valores e ao poder. O ambiente também desempenha papel fundamental, uma
1. LAROCHE, Hervé, NIOCHE, Jean-Pierre. L'approche cognitive de la stratégie d'entreprise. Revue Française de Gestion, juin-août 1994, p.64-78; MILLIKEN, Frances J., LANT, Theresa K. Past performance, interpretations, and strategic choice. In: SHRIVASTAVA, Paul, HUFF, Anne, DUTTON, Jane (Eds.). Advances in Strategic Management. Greenwich, Jai Press, v.7, 1991; HININGS, C. R., GREENWOOD, Royston. The Dynamics of strategic change. New York: Basil Blackwell, 1989; MILLER, D., FRIESEN, P. H. Organizations: a quantum view. Englewood Cliffs: Prentice-Hall, 1984.

2. LAROCHE, Hervé, NIOCHE, Jean-Pierre. Op. cit.; JOHNSON, G. Strategic change and the management process. Oxford: Blackwell, 1987

3. SENGE, Peter. A quinta disciplina. 11.ed. São Paulo: Makron Books, 1996; CALORI, Roland, JONHSON, Gerry, SARNIN, Philippe. CEO's cognitive maps of the organization. Strategic Management Journal, v.15, 1994, p.437-57.

4. De acordo com Walsh e Fahey, não há consenso entre os analistas sobre 0 conceito-chave da teoria da cognição organizacional: mapa mental, quadros de referência, esquemas interpretativos, estruturas cognitivas, mapas cognitivos ou modelos mentais são todos mutuamente substitutivos, com algumas nuances. Cfr. WALSH, J. P., FAHEY, L. The role of negociated belief structures in strategy making. Journal of Management, 12, 1986, p.325-38 
O AVANÇO DA TECNOLOGIA DA INFORMAÇÃO, A DESREGULAMENTAÇÃO DA ATIVIDADE FINANCEIRA, OS ACORDOS DE REMOÇÃO MÚTUA DE BARREIRAS COMERCIAIS ENTRE PAÍSES, ENTRE OUTROS, CONFIGURAM MUDANÇAS SIGNIFICATIVAS NO AMBIENTE EMPRESARIAL DESTE FINAL DE SÉCULO.

5. KANTER, Rosabeth M., STEIN, Barry A., JICK, Todd D. The challenge of organizational change: how companies experience it and leaders guide it. New York: The Free Press, 1992.

6. BARR, Pamela S., STIMPERT, J. L., HUFF, Anne S. Cognitive change, strategic action, and organizational renewal. Strategic Management Journal, v.13, 1992, p.15-36.

7. MILLIKEN, Frances J., LANT, Theresa K. Op. cit.

8. HININGS, C. R., GREENWOOD, Royston. Op. cit. vez que sua dinâmica de transformação influencia a interpretação dos dirigentes e a ação organizacional. À medida que certas ações se ajustam às demandas ambientais e propiciam sucesso empresarial, as organizações, por meio de mecanismos de reforço e de aprendizagem, tendem a persistir em tais ações. Com o passar do tempo, essas ações bem-sucedidas podem dar origem a padrões de atuação que, ao reforçarem valores vigentes, configuram a orientação estratégica.

Assim, processos de reforço e de aprendizagem possibilitam maior conexão entre a organização e o ambiente, em caso de sucesso empresarial. A organização, em tais circunstâncias, procura manter a sua orientação estratégica, valorizando a perspectiva de mudança incremental: pequenos ajustes aqui e acolá. A manutenção da postura estratégica propicia coerência e segurança à organização em seu relacionamento com o ambiente e tende a perdurar na ausência de mudanças ambientais profundas.

Não é o caso nos últimos anos. O ambiente organizacional é cada vez mais dinâmico e a velocidade das mudanças não encontra precedentes na história da sociedade humana. O advento das modernas tecnologias de telecomunicação e de informática, a desregulamentação financeira, a transnacionalização da atividade econômica, o crescimento significativo do comércio exterior, entre outros, todos constituem fatores de turbulência ambiental. Esses fatores levam à necessidade de mudanças substanciais nas organizações; ajustes incrementais, na maioria das vezes, revelam-se insuficientes para garantir a competitividade e a sobrevivência. Em tais circunstâncias, a reorientação estratégica ganha destaque. Reorientação estratégica consiste na modificação da estrutura, dos processos e/ou da cultura da organização, resultante de adaptações ambientais, de alterações internas como crescimento e ciclo de vida ou de disputas de poder, a fim de possibilitar a consecução dos objetivos de maneira mais eficaz. ${ }^{5}$

No entanto a pesquisa organizacional vem demonstrando que, por mais premente que se revele a necessidade de reorientação estratégica, as organizações tendem a persistir em estratégias anteriores. De modo geral, empresas bem-sucedidas encontram dificuldades em reorientar prontamente suas estratégias de ação diante de novas circunstânci- as ambientais; inclinam-se a adiar as mudanças estratégicas até a ocorrência de situação de crise, quando já se passou o melhor momento de implementá-las. Em síntese: a reorientação, quando ocorre, é adiada o quanto possível. Tal constatação é relevante, porquanto, como adequadamente observam Barr, Stimpert \& Huff, ${ }^{6}$ o atraso em mudar a estratégia pode conduzir a ações ineficazes no novo contexto ambiental e resultar no declínio da organização.

Ao que parece, o adiamento na implementação da reorientação estratégica decorre de quatro fatores interligados, conforme se afirmou na introdução deste artigo: a) a existência de reservas financeiras e de reservas psicológicas, b) a estabilidade dos esquemas interpretativos e das estruturas organizacionais, c) as deficiências de aprendizagem e a existência de mecanismos de atribuição e d) o contexto institucional de referência da organização.

A persistência das organizações no comportamento passado, segundo Milliken \& Lant, ${ }^{7}$ decorre tanto de reservas financeiras quanto de reservas psicológicas. As reservas financeiras auxiliam a manutenção das estratégias à medida que, geralmente, o sucesso anterior proporciona margens que permitem a sobrevivência da empresa por algum tempo nas novas condições, tempo suficiente para os dirigentes pensarem que as dificuldades são temporárias. As reservas psicológicas levam os dirigentes a supor que serão capazes de superar sozinhos quaisquer obstáculos que se apresentem.

Hinings \& Greenwood ${ }^{8}$ afirmam que a estabilidade dos esquemas interpretativos e das estruturas organizacionais também tende a atrasar a reorientação estratégica. Três elementos contribuem para tanto: a monitoração seletiva, os cálculos de custo-benefício e as disputas políticas. De acordo com esses autores, o primeiro elemento resulta da constatação de que estruturas e processos organizacionais são desenhados para monitorar seletivamente o ambiente e, portanto, induzem à seleção de determinadas informações em detrimento de outras, podendo, portanto, perder informações críticas. Os cálculos de custo-benefício consistem na tendência ao adiamento de determinada mudança até o ponto em que os custos de não implementá-la sejam maiores do que os de implementá-la: "Mudanças potencialmente disruptivas tendem a ser adiadas até que os custos de não reestruturar se trans- 
formem em suficientemente altos para justificar uma mudança estrutural ampla, requerida para restabelecer a harmonia entre os elementos estruturais". ${ }^{9}$ As disputas políticas, por sua vez, envolvem o jogo de interesses para adquirir e manter recursos escassos, podendo representar forte oposição a mudanças mais profundas. ${ }^{10}$

Em estreita relação com a estabilidade dos esquemas interpretativos estão as deficiências de aprendizagem e a existência de mecanismos de atribuição. ${ }^{11}$ Conforme Senge, ${ }^{12}$ deficiências de aprendizagem decorrem da evidência de que, embora se possa aprender com os erros, é assaz freqüente que as conseqüências dos atos ocorram em futuro remoto ou até mesmo longe da área em que os erros efetivamente ocorreram na organização; desse modo, não é possível estabelecer relações confiáveis de causa e efeito. Já os mecanismos de atribuição referemse à constatação, em numerosos estudos, ${ }^{13}$ de que os dirigentes tendem a atribuir desempenhos positivos da organização ao próprio esforço, enquanto os desempenhos negativos são atribuídos a fatores externos; assim, é natural que mecanismos de atribuição dificultem a aprendizagem, uma vez que podem impedir a organização de investigar as verdadeiras causas de seu desempenho. Ambos, de certa forma, contribuem para criar obstáculos à reorientação estratégica.

$\mathrm{O}$ conceito de contexto institucional de referência é o quarto fator que pode explicar a tendência das organizações a adiarem mudanças estratégicas. Muitas organizações trabalham de forma equivocada seu relacionamento com o ambiente, quer pela compreensão estreita do que constitui o ambiente, quer pela definição do que vem a ser seu contexto institucional de referência. Em relação ao primeiro aspecto, Machado-da-Silva \& Fonseca $^{14}$ observam que, de maneira geral, se considera como ambiente apenas os ambientes técnicos, ou seja, aqueles espaços cuja dinâmica de funcionamento se desencadeia por meio da troca de bens ou serviços, de modo que as organizações que neles se incluem são avaliadas pelo processamento tecnicamente eficiente do trabalho; o ambiente, contudo, também é constituído pelos ambientes institucionais que se caracterizam pela elaboração e pela difusão de regras e procedimentos que proporcionam às organizações legitimidade e suporte con- textual. Para esses autores é fundamental que se entenda que a natureza da atividade de cada organização determina a maior ou a menor importância de cada um desses ambientes (técnicos ou institucionais), como facetas de uma mesma dimensão, na formulação das estratégias de ação. Por exemplo: indústrias tendem a se modelar mais pelos ambientes técnicos, uma vez que o controle ambiental é exercido sobre os resultados em termos de quantidade e qualidade de bens; já hospitais precisam considerar fortemente os ambientes institucionais, uma vez que o controle ambiental incide sobre estruturas e práticas, sobre a adequação da forma organizacional às pressões sociais; em situação intermediária encontra-se o setor bancário, que parece sofrer pressões ambientais de caráter técnico e institucional em igual intensidade. Quanto ao segundo aspecto, Machado-da-Silva \& Fonseca ${ }^{15}$ afirmam que muitas organizações têm dificuldade em entender que ambientes técnicos e institucionais podem ser visualizados em diversos níveis de análise: local, regional, nacional e internacional. Cada organização, diante da necessidade de definir estratégias de ação, orienta-se pelo contexto institucional no nível que mais se coaduna com sua trajetória e, portanto, com sua lógica interior, isto é, com os esquemas interpretativos de seus dirigentes. Em princípio, a organização mais competitiva é aquela em que seus dirigentes possuem mentalidade internacional e, como tal, adotam o padrão de concorrência internacional como base para definir estratégias de ação. Todavia, uma organização que detenha trajetória de sucesso com suporte em estratégias alinhadas com o contexto institucional de referência nacional, por exemplo, pode encontrar dificuldade em adotar práticas legitimadas em contexto institucional mais amplo, mesmo quando esse contexto passa a ter maior relevância em decorrência de mudanças no quadro de concorrência mundial.

Em suma, a força dos componentes do contexto institucional de referência e sua ligação com os esquemas interpretativos do grupo de dirigentes, detentor do domínio da organização, podem contribuir para a manutenção de estratégias passadas, à medida que podem levar a que se subestimem os sinais de mudança ambiental provenientes de contexto mais amplo.
9. MILLER, D., FRIESEN, P. H. Op. cit.

10. HININGS, C. R., GREENWOOD, Royston. Op. cit.

11. Deficiências de aprendizagem e mecanismos de atribuição podem ser considerados como fatores que contribuem para a estabilidade dos esquemas interpretativos. Optou-se em apresentálos à parte apenas por questão de ênfase.

\section{SENGE, Peter. Op. cit.}

13. HUFF, Anne S., SCHWENCK, Charles. Bias and sensemaking in good times and bad. In: HUFF, Anne S. (Ed.). Mapping strategic thought. Chichester: Wiley and Sons, 1990.

14. MACHADO-DA-SILVA, Clóvis, FONSECA Valéria. Competitividade organizacional: uma tentativa de reconstrução analítica. In: XX Encontro Anual da ANPAD, 1996, Angra dos Reis. Anais Angra dos Reis: ANPAD, 1996a, v. Organizações II, p.207-22.

15. Idem, ibidem. 


\section{CONSIDERAÇÕES METODOLÓGICAS}

Estudar os fatores que determinam o adiamento de reorientações estratégicas implica, necessariamente, considerar o lado subjetivo das organizações e de seu grupo dirigente: valores e crenças que compõem seus esquemas interpretativos; grupos e formas de distribuição do poder; e modos de interpretação da realidade. Em pesquisas dessa natureza, em que o foco é o processo de mudança, é aconselhável que se utilize a perspectiva longitudinal de análise, investigando a organização ao longo de determinado intervalo de tempo; no presente estudo considerou-se o período compreendido entre 1992 e 1996. Também é conveniente que se diversifiquem as fontes de evidência; para tanto, foram utilizadas fontes secundárias e primárias de dados com variação nas formas de análise: os dados secundários foram obtidos mediante a verificação de dez relatórios de administração do Banco Bamerindus, bem como da leitura de revistas e de jornais específicos da área financeira, todos publicados no período em estudo; os dados primários foram coletados por meio de entrevistas semi-estruturadas com dirigentes da alta administração, escolhidos mediante o uso da técnica de amostragem intencional.

Pode-se objetar que relatórios da administração não são o material ideal para se avaliar os esquemas interpretativos dos dirigentes, principalmente em anos mais recentes, em que esses relatórios foram preparados pela área de Relações Públicas e, depois, repassados para os dirigentes, que só os conferiram e os assinaram. Certo viés pode estar presente, como, por exemplo, o relacionado à escassez de informações depreciativas sobre o grupo dirigente.

Apesar das limitações desse tipo de documento, há poucas fontes alternativas que forneçam insights sobre mudanças em esquemas interpretativos ao longo do tempo: os relatórios da administração têm a vantagem de terem sido escritos em momentos específicos do período de interesse; além disso, contêm, a partir de um ponto de vista privilegiado, as opiniões e os conceitos dos dirigentes, uma vez que resultam do que é tratado nas reuniões de diretoria; também representam, de maneira razoável, o entendimento das circunstâncias de decisão no nível organizacional de análise ${ }^{16} \mathrm{o}$ qual constitui o foco do presente estudo. Cabe ressaltar que o cruzamento dos dados dos relatórios com os obtidos por meio das entrevistas semiestruturadas possibilitou, até certo ponto, o controle de viés.

Os dados primários e secundários da pesquisa foram tratados e analisados a partir dos quatro fatores mencionados anteriormente $\mathrm{e}$ detalhados a seguir, os quais procuram explicar por que organizações bem-sucedidas tendem a encontrar dificuldade em reorientar prontamente suas estratégias diante de novas circunstâncias ambientais.

A existência ou não de reservas financeiras foi avaliada diretamente nos relatórios da administração, utilizando-se os dados referentes à rubrica lucro líquido. Por sua vez, as reservas psicológicas foram verificadas por meio de entrevistas com os dirigentes e mediante o grau de incidência de afirmações constantes dos relatórios, do tipo: " $O$ Bamerindus considera-se preparado para a realidade desse novo Brasil de economia estável (...)" (Relatório da Administração de dezembro de 1995).

Os esquemas interpretativos foram identificados mediante o uso de múltiplas fontes de evidência. Inicialmente, valores foram levantados a partir da análise de conteúdo dos relatórios da administração; o procedimento específico consistiu na construção de mapas causais, a partir do reconhecimento de relações de causa e efeito, de acordo com determinadas categorias de codificação propostas por Huff, Narapareddy \& Fletcher; ${ }^{17}$ a frequiência de determinado conceito em relatórios sucessivos foi tomada como indicadora da manifestação de um valor do grupo dirigente; conforme Bowman, ${ }^{18}$ organizações tendem a mencionar mais em seus relatórios os aspectos que mais valorizam. ${ }^{19}$ Os valores apreendidos mediante a análise de conteúdo foram confirmados ou não, com base nas entrevistas semi-estruturadas com os dirigentes e, também, por meio da análise das estratégias do Bamerindus no período. Por sua vez, a estrutura organizacional foi verificada com base na análise documental e nas entrevistas com os dirigentes, em que se procurou avaliar possíveis modificações nos componentes organizacionais, levadas a efeito no período em exame.

A identificação de mecanismos de atribuição e de deficiências de aprendizagem deu-se mediante a análise das explicações apresenta- 
das pelos dirigentes às causas de seus sucessos e de seus fracassos. Em particular procurou-se observar se ocorreu o que se prevê na literatura especializada sobre o assunto, isto é: atribui-se bom desempenho a fatores internos e desempenho inadequado a fatores externos.

Finalmente, o contexto institucional de referência dos dirigentes foi avaliado com base nos relatórios da administração e nas entrevistas semi-estruturadas. Nessa fase da análise, procurou-se identificar a ênfase atribuída a conceitos de referência local, regional, nacional e internacional. Partiu-se do pressuposto de que a freqüência de manifestação em relação a cada nível pode revelar o contexto institucional de referência da organização.

\section{DESCRIÇÃO DA SITUAÇÃO EM ESTUDO}

O Banco Bamerindus situava-se, no período em estudo, entre as cinco maiores instituições bancárias do País, conforme vários indicadores: a) segundo lugar em número de agências, b) terceiro em patrimônio líquido e c) terceiro em ativos. O número de funcionários diminuiu consideravelmente no período: cerca de 35.000 nos anos iniciais do estudo; aproximadamente 25.000 em anos mais recentes.

No período anterior ao Plano Real, o Bamerindus caracterizou-se pela postura inovadora e audaciosa no lançamento de produtos e serviços; por exemplo, introduziu a conta corrente remunerada, que corrigia com juros e com correção monetária o valor depositado em conta corrente. Nessa e em outras iniciativas, adotou postura de vanguarda, ocupando posição de referência para os demais bancos de varejo do País.

Todavia, a postura de vanguarda do Bamerindus durante esse período esteve sempre condicionada à estratégia de captação financeira por meio da expansão da rede de agências, com a conseqüiente aplicação dos recursos em títulos públicos. Tratava-se de prática bastante utilizada pelos bancos do País, com eficácia inquestionável em regime de alta inflação. Conforme afirmou um dirigente entrevistado, "Na economia inflacionária, o sucesso do Banco está na razão direta de sua capacidade de aumentar o volume de captação, o que supõe incremento na rede de agências e, portanto, crescimento nos custos fixos. O incremento nos custos fixos era mais do que compensado pelo aumento na captação". ${ }^{20}$

$\mathrm{Na}$ mesma linha de raciocínio, outro dirigente justifica a estratégia de captação de recursos implementada pelo Banco, complementando com o depoimento seguinte: "Numa economia inflacionária, a visão do negócio é distorcida. Você não se preocupa com a competência, mas com a oportunidade e com a massa crítica de recursos, o que gera uma bola de neve. Nem sempre quem ganha mais é mais eficiente: ganha quem tem uma maior participação especulativa no mercado".

A estratégia adotada pelo Bamerindus durante o período de altos índices de inflação pode ser visualizada na Figura 1. A expansão da rede de agências propiciava maior captação financeira, que, assim, disponibilizava mais recursos para aplicação em títulos governamentais; o ganho financeiro daí resultante era investido para expandir ainda mais a rede de agências, visando a aumentar a captação de recursos; e o ciclo se repetia de forma crescente.

\section{Figura 1 - Estratégia básica do Bamerindus no período de alta inflação}

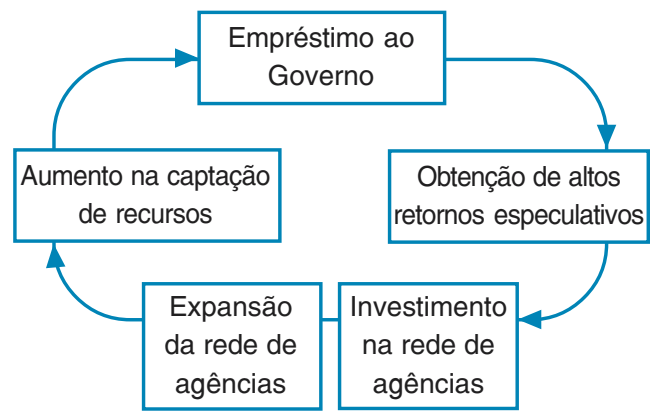

O Plano Real, implantado a partir de 28 de fevereiro de 1994, significou uma iniciativa bem-sucedida do Governo para o controle da inflação, que não rompeu com as expectativas dos agentes econômicos como os planos anteriores haviam feito. A estabilização da economia resultante da implementação do Plano Real começou a fechar as portas ao fácil ganho especulativo. Como bem atesta o depoimento de um dirigente: "Os bancos viram-se, então, com uma ampla rede de agências, um capital imobilizado, que aumenta significativamente os custos fixos, $e$ uma estrutura inchada. Com a queda da receita, não houve outro modo de retomar a
AS ESTRATÉGIAS ORGANIZACIONAIS SÃO USUALMENTE DELINEADAS A

PARTIR DE UM CONJUNTO DE FORÇAS QUE SE SUSTENTAM, DE UM LADO, OS VALORES E CRENÇAS COMPARTILHADOS PELO GRUPO DE DIRIGENTES E, DE OUTRO, A FORMA DE DISTRIBUIÇÃO DO PODER ORGANIZACIONAL ENTRE OS MEMBROS DA COALIZÃO DOMINANTE.
20. As afirmações entre aspas foram extraídas das entrevistas com os dirigentes ou dos relatórios da administração; no segundo caso, indica-se o relatório citado. 
competitividade senão pela redução dos custos e aumento da eficiência".

Assim, o advento do Plano Real implicou a necessidade de mudanças de natureza estratégica no Banco Bamerindus. Vale ressaltar que entre a implementação do Plano Real e o início da reorientação estratégica do Bamerindus decorreu um intervalo de quase dois anos. A primeira mudança significativa, em resposta às novas circunstâncias ambientais, ocorreu em dezembro de 1995, com a implementação da reforma patrimonial da corporação. Na ocasião, desvinculou-se o Banco de outras empresas do grupo, como a fábrica de papel e a seguradora. A segunda mudança significativa ocorreu em março de 1996 e foi impulsionada notadamente pela crise de liquidez do Bamerindus. Entre a superintendência e as 27 diretorias (áreas fim, áreas meio e diretorias de regionais) foram instituídas quatro coordenações de diretorias: Internacional e Finanças; Administração; Produção; e Crédito. A partir da criação desse novo nível hierárquico, somente os quatro coordenadores tinham acesso direto à superintendência. De acordo com alguns entrevistados, as coordenações foram instituídas para liberar o principal executivo, conferir maior agilidade ao processo decisório e permitir maior controle das despesas administrativas do Banco. Os coordenadores passaram a funcionar como ponte de ligação entre o superintendente e os demais diretores do Bamerindus. A terceira mudança levada a efeito consistiu na reorientação do Banco para atividades de risco, conforme depoimentos dos entrevistados: "Os bancos brasileiros desaprenderam a emprestar dinheiro, pois durante muito tempo só emprestaram para o Governo. Antes do periodo inflacionário, o conhecimento sobre como fazer bons créditos era transmitido de gerente para gerente; hoje falta experiência ao pessoal para isso" ou "Os gerentes esqueceram a malícia de emprestar: antes de emprestar, vá na fábrica, olhe os estoques, os pedidos em carteira, descubra seus amigos e veja se é conhecido na praça (...)".

O Bamerindus procurou resgatar tais práticas notadamente através do credit scoring, ou sistemas estatísticos, utilizados normalmente por bancos no exterior para mensuração do risco a partir de certos atributos do cliente, tais como renda, estado civil, estabilidade no emprego. O Banco obteve péssimos resultados com o resgate dessas práticas. A explicação dada por um dirigente é a que se segue: "Há uma série de variáveis exógenas que influenciam o comportamento do tomador, como a política de crédito do Governo. Assim, mesmo clientes com score impecável tiveram problemas de liquidez e não conseguiram pagar".

Por fim, a estabilização da economia também determinou o redirecionamento e o fortalecimento das atividades de crédito de modo emergencial. $\mathrm{O}$ fato de o Bamerindus não se ter preparado com a antecedência devida para uma situação de baixos índices de inflação deixou-o em delicada situação financeira, da qual não mais conseguiu sair.

É sugestivo que o controle da inflação, ou seja, a diminuição do índice para níveis considerados toleráveis, tenha surpreendido o Bamerindus com volume de operações de crédito insuficientes para cobrir seus custos. A manutenção das práticas do período de alta inflação até a véspera do Plano Real e o atraso posterior em reorientar sua estratégia de ação para torná-la adequada às novas circunstâncias ambientais, decorrentes da estabilização econômica, parecem sugerir como a força dos esquemas interpretativos vigentes pode impedir a organização de enxergar mudanças visualizadas com antecedência em diversos segmentos da sociedade.

\section{ANÁLISE DA SITUAÇÃO EM ESTUDO}

O Bamerindus claramente demorou para realizar as mudanças estratégicas que se impunham para o seu melhor ajustamento às novas circunstâncias ambientais. Seguramente havia necessidade de: atribuir maior ênfase à produtividade e à eficiência; revisar a estratégia de expansão da rede de agências como instrumento para aumento da captação financeira; e fortalecer as atividades de crédito. Cumpre saber por que isso ocorreu. Ao que parece, os quatro fatores tratados anteriormente fornecem adequada explicação para o atraso na indispensável mudança estratégica do Banco, todos eles relacionados à constatação resultante de vários estudos de que organizações bem-sucedidas tendem a encontrar dificuldades em reorientar prontamente suas estratégias diante de novas circunstâncias ambientais. Na seqüência, realiza-se a análise de cada um dos fatores que parecem oferecer resposta ao problema da presente pesquisa. 
1. Existência de reservas financeiras e de reservas psicológicas

No período considerado na presente pesquisa, o Bamerindus obteve lucros crescentes até 1995, conforme se pode observar pela verificação do seu patrimônio líquido, constante da Tabela 1. no foram imediatos, gerando recuperação da atividade econômica e perspectivas otimistas" (Relatório da Administração de dezembro de 1994). Deve-se destacar que nesse ano o Banco obteve ótimo desempenho, uma vez que os efeitos do plano econômico não se fizeram sentir imediatamente. Além disso, o Plano Real teve grande aceitação popular; não

Tabela 1 - Patrimônio líquido do Bamerindus (em milhares de dólares)

\begin{tabular}{|c|c|c|c|c|c|}
\hline & 1992 & 1993 & 1994 & 1995 & 1996 \\
\hline PLT & 673.622 & 764.865 & 1.008 .180 & 1.239 .767 & 1.057 .000 \\
\hline
\end{tabular} Fonte: Balanços Anuais.

O Plano Real, implementado em 1994, não impediu a continuidade da expansão imediatamente, uma vez que não rompeu contratos estabelecidos, e o Banco recebeu os valores correspondentes a títulos negociados anteriormente. No entanto, como se observa na Tabela 2, a taxa de crescimento decaiu significativamente de 1994 para 1996. seria conveniente que o Bamerindus se colocasse em posição contrária à sociedade mais ampla. Deve-se recordar que os relatórios anuais são, também e de certo modo, uma encenação para o público.

A seguir, o Banco começa a sentir as dificuldades decorrentes do Plano Real, o que coloca em evidência a segunda atitude: não di-

Tabela 2 - Taxa de crescimento do patrimônio líquido do Bamerindus (em milhares de dólares)

\begin{tabular}{|l|c|c|c|c|}
\hline & $1992-1993$ & $1993-1994$ & $1994-1995$ & $1995-1996$ \\
\hline Taxa de crescimento & $13,5 \%$ & $31,8 \%$ & $18,7 \%$ & $-17,3 \%$ \\
\hline Fonte: Balanços Anuais.
\end{tabular}

A implantação do Plano Real coincidiu com o momento de rentabilidade máxima do Bamerindus. No primeiro semestre de 1994, o Banco obteve o lucro recorde de $\mathrm{R} \$ 61,1$ milhões, correspondente ao crescimento de $76,3 \%$ sobre o lucro do primeiro semestre de 1993. Assim, a introdução do plano econômico deu-se em momento em que o Banco estava bem provido em termos de reservas financeiras. Os dados apresentados permitem que se afirme a existência de reservas financeiras suficientes para o Bamerindus sobreviver por algum tempo, no período em exame, sem necessariamente rever suas estratégias de ação.

A presença de reservas psicológicas também pôde ser observada mediante a análise dos relatórios anuais e do conteúdo das entrevistas semi-estruturadas com os dirigentes. Da análise de conteúdo dos relatórios foi possível registrar duas atitudes em relação ao Plano Real. A primeira delas foi de aprovação: “(...) os efeitos positivos do Pla- minui a aprovação, mas aponta as exigências que o Real traz para os agentes econômicos e, em particular, para as instituições financeiras.

"As medidas monetárias adotadas pelo Governo no ano passado para consolidar a estabilização da economia exigiram um forte esforço de adaptação a uma nova realidade. No caso específico do sistema financeiro, o estreitamento da liquidez para pessoas e empresas refletiu-se diretamente nos bancos e a situação agravou-se ainda mais quando o Banco Central se viu obrigado a intervir em algumas instituições" (Relatório da Administração de dezembro de 1995).

Em diversas passagens dos relatórios do período em estudo, entre as quais estão as duas que se seguem, pôde-se comprovar a presença de reservas psicológicas: " $O$ Bamerindus está pronto para compartilhar dessa nova fase de crescimento e estabilidade, graças aos investimentos em recursos humanos e tecnológicos (...)" (Relatório da Administração de dezembro de 1994) 
e "Confiante no futuro, o Bamerindus continua com a política de investimentos, renovação tecnológica e melhoria nos padrões de qualidade" (Relatório da Administração de junho de 1995).

As entrevistas semi-estruturadas realizadas com os dirigentes permitiram corroborar a existência de reservas psicológicas ob- variação ao longo do período. A triangulação desses resultados com as entrevistas semi-estruturadas realizadas com os dirigentes possibilitou confirmar os valores compartilhados e compreender as mudanças que se verificaram no período em estudo. ${ }^{21}$ Os resultados podem ser visualizados no Quadro 1:

Quadro 1 - Valores dos dirigentes do Bamerindus no período de 1992 a 1996

\begin{tabular}{|l|l|}
\hline Valores & $\begin{array}{l}\text { Análise dos relatórios da administração, } \\
\text { mapas causais e entrevistas }\end{array}$ \\
\hline Postura inovadora/criativa/arrojada & Orientação básica não mudou. \\
\hline Preocupação com clientes/orientação para marketing & Orientação básica não mudou. \\
\hline Importância atribuída à tecnologia & Orientação básica não mudou. \\
\hline Valorização de pessoal & Orientação básica não mudou. \\
\hline Redução de custos/produtividade & Preocupação maior a partir do Plano Real. \\
\hline Postura face ao risco & Mudança a partir do Plano Real. \\
\hline
\end{tabular}

servadas nos relatórios da administração. Tal presença é evidente nos depoimentos dos dirigentes, que se apoiavam na suposição de que a mudança econômica não seria definitiva: "Recebemos o Plano Real com certo receio. Afinal, o Governo já tinha intervindo quatro vezes na economia, em menos de oito anos, sem resultado" ou "Esta não é a primeira nem será a última dificuldade que o Bamerindus enfrenta e, como as demais, será superada".

É possível observar que, ao se apoiarem no pressuposto de que as dificuldades seriam temporárias e que seriam capazes de superar sozinhos os obstáculos, os dirigentes não se preocuparam com a reorientação estratégica na velocidade requerida pelas novas circunstâncias ambientais. Assim, os dados constantes das Tabelas 1 e 2 em conjunção com os trechos dos relatórios e dos depoimentos dos dirigentes permitem que se afirme a importância do primeiro fator explicativo para o comportamento do Bamerindus, ou seja, a existência de reservas financeiras e de reservas psicológicas.

\section{Estabilidade dos esquemas interpre- tativos e das estruturas organizacionais}

A construção de mapas causais a partir 21. Para melhor entendimento da metodologia utilizada, vide FERNANDES Bruno H. R. e MACHADO-DA-SILVA, Clóvis L. (1997).
A análise que resultou nos valores sumariados no Quadro 1 parece confirmar a estabilidade dos esquemas interpretativos. Tal constatação parece verdadeira, mesmo com a ressalva de que a implementação do Plano Real despertou os dirigentes para a necessidade de reorientação estratégica no que diz respeito à postura em relação às operações de crédito e à preocupação com custos e com produtividade, uma vez que até em relação a esses aspectos a mudança não foi profunda: "[No início do Plano Real] a cabeça das pessoas não mudou muito. Fomos formados numa cultura inflacionária: estamos acostumados com isso. Hoje temos um preço de \$10,00, amanhã de $\$ 12,00$, e aceitamos isso naturalmente. E isso é um absurdo. Não há atividade produtiva que resista a uma majoração de $20 \%$ em роисо tempo".

Observe-se que a primeira mudança significativa no Bamerindus (reforma patrimonial da corporação) ocorreu em dezembro de 1995, e a segunda (modificação da estrutura organizacional com a criação de quatro coordenações de diretorias), em março de 1996. Tendo em vista que fevereiro de 1994 é o mês de referência do início do Plano Real, isso significa que tais mudanças aconteceram com atraso de quase dois anos. Dessa forma, os dados parecem comprovar a estabilidade dos esquemas interpretativos e das estruturas organizacionais, que con- 
siste no segundo fator explicativo da presente pesquisa.

\section{Deficiências de aprendizagem e exis- tência de mecanismos de atribuição}

A leitura dos relatórios da administração revelou a existência de mecanismos de atribuição, com algumas nuances. Nos relatórios do início do período são freqüentes as referências aos bons resultados do Bamerindus como decorrentes do esforço e da competência da organização: "O sucesso de nossa administração ao final de mais um semestre está ratificado pela performance e pela boa imagem que o Bamerindus desfruta perante sua clientela e público em geral" (Relatório da Administração de junho de 1992) e, também, "Os bons resultados agora apresentados devem-se à política consciente e agressi$v a$ de atendimento a todos os segmentos do mercado, com ênfase no setor produtivo, aliada à costumeira prudência na gerência das nossas operações. Tais esforços, em perfeita sintonia com os objetivos governamentais, redundaram em expressivos crescimentos reais em quase todas as nossas carteiras" (Relatório da Administração de junho de 1993).

Já nos relatórios correspondentes ao período de implementação do Plano Real (junho e dezembro de 1994), não se mencionam mais os bons resultados. A atitude geral que transparece nos relatórios é de expectativa: "Para o Bamerindus, as mudanças ocorridas ou futuras não devem implicar em modificações profundas, pois o Banco já vinha sistematicamente procedendo ajustes em suas estruturas, investindo na modernização tecnológica, reengenharia de processos e sistemas, capacitação profissional e redução de custos operacionais" (Relatório da Administração de junho de 1994).

Por fim, nos últimos relatórios aparecem referências a fatores externos que prejudicam o desempenho do Banco, em especial os boatos sobre sua situação financeira: " $A$ crise [do sistema financeiro], alimentada por boatos, influiu no desempenho do Bamerindus, mas não teve maiores proporções graças à sua estrutura operacional" (Relatório da Administração de dezembro de 1995), "A transparência das ações implementadas pelo Banco contribuiu para sua estabilidade financeira e seu desempenho só foi prejudicado, em alguns momen- tos, por boatos e notícias infundadas que, obviamente, não se confirmaram" (Relatório da Administração de junho de 1996) e " $O$ Bamerindus é um dos bancos que mais têm sido atingido com a publicação, em alguns veículos de comunicação, de notícias infundadas e levianas a seu respeito e comparações irresponsáveis com instituições insolventes. A situação do Bamerindus hoje é mais favorável do que a apresentada no final de dezembro passado, particularmente com relação à captação de recursos, mas é claro que esse processo de boatos e divulgação prejudica os esforços de recuperação" (Relatório da Administração de dezembro de 1996).

Assim, a análise de conteúdo dos relatórios, complementada pelas entrevistas com os dirigentes, confirma a tendência à atribuição de fracassos a causas externas, conforme se menciona na literatura especializada da área de organizações. No caso, os boatos que atrapalham o desempenho do Bamerindus. De outro lado, é interessante observar que o Banco não assume desempenho ruim no período: teria sido prejudicado só em alguns momentos. Essa evidência difere do que se verificou em outros estudos, em que a organização reconhece desempenho insuficiente, atribuindo-o à conjuntura. Tal resultado pode refletir certa peculiaridade de instituições bancárias, que são mais vulneráveis à perda de credibilidade do que organizações de vários outros setores: o desempenho inadequado que se assume publicamente pode implicar uma corrida dos clientes para sacar os seus depósitos, levando a instituição já em processo de declínio à deterioração, de forma mais rápida, das condições que ainda a sustentam. Pode-se concluir, portanto, que o terceiro fator explicativo da problemática da presente pesquisa foi corroborado em parte no que concerne à presença de mecanismos de atribuição.

\section{Contexto institucional de referência da organização}

A análise dos dados no estudo em tela revelou a expansão, mesmo que incremental, do Bamerindus no que se entende como sendo seu âmbito de atuação. Isso pôde ser constatado pelo aumento de conceitos internacionais mencionados nos relatórios ao longo do período em exame: no início, a referência a conceitos internacionais é de aproximadamente 15 por relatório; já no final, os 
conceitos internacionais aparecem cerca de 30 vezes nos relatórios da administração. ${ }^{22}$ A ampliação no que se concebe como sendo o domínio de atuação do Bamerindus parece ser conseqüência da própria expansão internacional do Banco no período. ${ }^{23}$

No entanto, o alargamento da concepção de domínio do Banco Bamerindus não teve implicações profundas até 1995 . No período anterior ao Plano Real, as peculiaridades do sistema financeiro nacional (altas taxas de inflação, constante intervenção do Governo na economia, caráter introvertido do mercado brasileiro e proibição a bancos estrangeiros de operarem no País) funcionaram como buffers que dificultaram a visão do Banco no sentido de considerar como referência uma realidade mais ampla, mesmo possuindo certa experiência internacional. As circunstâncias do contexto institucional de referência nacional impuseram-se como forças dominantes, e o Bamerindus desenvolveu estratégias bem-sucedidas para atuar nesse contexto de alta inflação. O sucesso dessas estratégias até fins de 1993 e início de 1994 propiciou a cristalização de valores nos esquemas interpretativos dos dirigentes em que o contexto institucional de referência nacional constituía ponto de partida e de chegada. Com a implementação do Plano Real, as novas circunstâncias ambientais decorrentes da estabilização da economia brasileira não foram interpretadas pelos dirigentes como passíveis de permanecerem por longo tempo, mas sim como temporárias, como já havia ocorrido com outros planos econômicos. No fundo, os dirigentes do Bamerindus apostaram no retorno das altas taxas de inflação, e perderam. A estreita relação entre esquemas interpretativos e contexto institucional de referência dificultou a pronta assimilação das novas circunstâncias resultantes da estabilização da economia, com o conseqüente atraso na reorientação estratégica do Banco. A experiência de atuação internacional em economias estáveis acabou sendo de pouca utilidade para o Bamerindus, no sentido de mudar os esquemas interpretativos de seus dirigentes, como bem atesta o seguinte depoimento do diretor da Área Internacional no período em estudo: "[Antes do Plano Real] tivemos dificuldade para transferir a experiência internacional para a área doméstica. O pessoal da área doméstica dizia que o que vale lá fora não se aplica aqui”.
Em síntese, as entrevistas com os dirigentes confirmaram a força do contexto institucional de referência nacional, que acabou contribuindo para o atraso da reorientação estratégica do Bamerindus, em face do aprisionamento dos esquemas interpretativos dos dirigentes à história de sucesso anterior da organização.

\section{CONSIDERAÇÕES FINAIS}

O caso do Bamerindus parece sustentar o quadro teórico de referência proposto neste estudo para explicar a mudança organizacional. As modificações que ocorreram no Banco até o final de 1995 foram de natureza incremental, apesar de novas circunstâncias ambientais estarem presentes desde 1994, pressionando em direção à reorientação estratégica da organização. Apenas quando o Bamerindus se viu em situação de crise, tentou levar a efeito as necessárias mudanças estratégicas; já havia passado, todavia, o melhor momento de implementá-las. O resultado do adiamento da reorientação estratégica do Banco ocasionou o agravamento da situação de crise, que culminou com sua situação de quase insolvência e, finalmente, com sua venda a grupo bancário internacional, em março de 1997.

Os fatores apresentados para explicar o comportamento de resistência à mudança estratégica no Bamerindus foram sustentados pelos dados do presente estudo. Conforme se pôde observar, o adiamento da reorientação estratégica do Banco deu-se pela existência de reservas financeiras e de reservas psicológicas, pela estabilidade dos esquemas interpretativos e das estruturas organizacionais, pela presença em parte de mecanismos de atribuição e pela força do contexto institucional de referência anterior da organização em articulação com os esquemas interpretativos dos dirigentes.

O caso-objeto do presente estudo parece ilustrar adequadamente determinada afirmação na área de administração: que o sucesso atual pode constituir-se em armadilha para o futuro da organização. Ao mesmo tempo, procura evidenciar os fatores que levam tal afirmação a se tornar possível. Estar consciente desses fatores é passo essencial para eliminar os obstáculos para o aprendizado organizacional conseqüente e para a implementação das mudanças necessárias à constante adaptação ambiental da organização. 